\title{
A Conceptual Framework for the Internalization of a Sport Object
}

\section{through Sport Video Gaming}

\author{
Min Soo Kim ${ }^{\mathrm{a}^{*}}$ \& Jeffery James \\ ${ }^{a}$ Senior researcher, Department of Sport Industry Research, Korea Institute of Sport Science, Republic of Korea \\ ${ }^{b}$ Professor, Department of Sport Management, Florida State University, USA
}

\begin{abstract}
As the sport marketplace has become competitive, sport organizations are challenged to attract and maintain sport consumers. Using sport video games as a marketing communication strategy may be a good way to reach young sport consumers due to the popularity of sport video games(SVGs). Based on Kim and Ross' findings (2006), it is believed that playing SVGs may foster a psychological connection with a sport team. The current study assumes the extent to which motives to play SVGs and a sense of presence contribute to explain a psychological connection with a sports team (i.e., internalization) based on the Fan Attitude Network (FAN) model (Funk \& James, 2004). The internalization model of a sport object through sport video gaming is proposed based on the review of literature. The model assumes that motives to play SVGs and a sense of presence contribute to explaining what variables contribute to a sport identity. The purpose of the study is to understand the influence of motives to play SVGs and a sense of presence on a sport identity. A theoretical model depicting the relationship between motives to play SVGs and a sport identity, the relationship between a sense of presence and a sport identity, and the interaction effect between motives and a sense of presence on a sport identity was proposed. Testing the proposed model would contribute to the understanding of what drives sport video gamers to facilitate personal connections with their favorite teams and guide implications for marketing communication practice.
\end{abstract}

Key words: internalization, fan attitude network (FAN), sport object, sport video gaming

\section{Introduction}

As the sport marketplace has become very competitive, sport organizations are challenged to attract and maintain sport consumers. Part of the challenge includes reaching and influencing a younger consumer

Submitted : 12 October 2021

Revised : 8 November 2021

Accepted : 17 December 2021

Correspondence : minkim@kspo.or.kr base such as Generation Y and Z (Gen-Y \& Z) although they are highly desirable targets for corporations (Bennett \& Lachowetz, 2004; Wheaton \& Thorpe, 2018). Gen-Y and $Z$ are coveted consumers by marketers and advertisers in part because Gen- $Y$ includes approximately 78 million members (Bennett, Henson, \& Zhang, 2003) and Gen Z is already 25.9\% of the U.S. population (Beall, 2016). Gen-Z constitutes 32 percent of the global population and became the 
largest generation in 2019 (Spitznagel, 2020). One idea for connecting Gen-Y and Z consumers to traditional sports is through sport video games because almost $65 \%$ of sport video gamers can be classified as members of Gen-Y (Bennett, Sagas, \& Dees, 2006) and racing games(61\%) and sport games(60\%) are favorite games of male Millennial gamers in 2019(ESA, 2020).

The connection between consumers and a sports team is important in the context of team loyalty because individuals with high degree of personal connection to a sports team are resistant to changing their favorite team, have a consistent and persistent attitude toward their favorite team (Funk \& James, 2001; 2006), are influential in recruiting others to become fans of the team (James, Kolbe, \& Trail, 2002), and are more likely to attend games (Wann \& Branscombe, 1993). Kim and Ross (2006) found that most sport video gamers were likely to select their favorite teams in real life when playing sport video games (SVGs). From this finding, it is assumed that playing SVGs may help to maintain a psychological connection with a sports team. A critical step for sport marketers is examining what drives sport video gamers to facilitate personal connections with their favorite teams; said another way, it is necessary to understand the extent to which motives and features of SVGs contribute to a sport identity. The Fan Attitude Network (FAN) model (Funk \& James, 2004) can be applied in order to answer these questions.

\section{The Fan Attitude Network (FAN) Model}

Funk and James (2004) proposed the Fan Attitude Network (FAN) model to suggest how the internalization of a sport object (i.e., a sport team, player) into one's self-identity, and the subsequent formation of a sport identity, has an impact on attitude formation and change toward the sport object. The internalization of a sport object can be thought as an extension of oneself (Funk \& James, 2004) and expected to produce team loyalty (Kolbe \& James, 2003). The concept of loyalty, a psychological connection to a sport team, is very important for sport organizations in order to achieve long-term business success and financial goals (Funk \& Pastore, 2000) because loyal customers provide sport organizations with a sustainable source of income.

The FAN model provides a conceptual framework from which to understand the formation of a psychological connection to a sports team (i.e., internalization). While this model was proposed to examine the attitude of sport fans toward a sport team in terms of sport spectating, it can be applied to sport video gaming because sport video gamers are also sport consumers (Kim \& Han, 2012). Going further, with recent versions of SVGs, individual can experience drafting, scouting, and even make business decisions such as franchise relocation. The realism and efforts to replicate "real life" sporting activities give gamers very realistic experiences. Murrell and Dietz (1992) suggested that individuals may form personal connections with sport teams without actual attending sporting events. Thus, it is suggested that individuals can develop and/or reinforce a psychological connection to a sports team through sport video gaming because it provides the experience of sport spectating. Thus, the purpose of the study was to understand the influences of motives to play SVGs and a sense of presence on a sport identity.

\section{Motives to play sport video games}

Funk and James (2004) suggested that dispositional needs of sport fans refer to psychological needs, personality traits and individual attributes, which are the catalysts that motivate people to create and develop a psychological connection to a sport object as a way to express their personal traits, attributes, characteristics, and self-concepts. Funk and James suggested that these characteristics are generally considered as the "motivational factors" that influence sport consumer 
behavior. Motivations to play SVGs and those to watch sport may be similar because both activities constitute sport consumption. Various motives to play SVGs such as fantasy, competition, drama, knowledge application, identification with sport, entertainment, social interaction, diversion, challenge, aggression, and aesthetics have been identified (Kim \& Kwon, 2010; Kim \& Ross, 2006). Funk and James suggested that "individuals may be motivated to form a psychological connection with a sport team and engage in particular behaviors in order to satisfy various dispositional needs" (p. 8). For example, playing a basketball video game as Michael Jordan can satisfy an individual's need for fantasy and provide an opportunity to create or facilitate a psychological connection with a sport object (e.g., the Chicago Bulls or Michael Jordan). Thus, the satisfaction of unmet needs may lead to the development or reinforcement of a sport identity (Funk \& James, 2004). It is assumed that individuals have different motives to play SVGs and the fulfillment of their unmet needs can lead to the development or reinforcement of a sport identity. It is necessary to examine the extent to which fulfillment of an individual's particular psychological needs for sport video gaming account for a sport identity in order to advance our understanding of sport consumption behavior related to sport video gaming.

Proposition 1: Motives to play sport video games directly contribute to a sport identity.

\section{Sport Identity}

James and Ross (2002) noted that an individual who becomes involved with a sport object (e.g., a sports team) is likely to have engaged in some sort of internalization process with regard to that object. Sport identity represents "the internalization of a sport object (e.g., sport, team, or player) into one's self-concept to fulfill dispositional needs” (Funk \& James, 2004, p. 12). It suggests that as an individual creates an association with a sport object through an internalization process, the sport object may become an integral part of his or her self-identity. That means an individual does not mererly follow and prefere a sport team, but he or she considers the sport team a part of himself/herself and the extenstion of the team. An expected outcome of the internalization process is team loyalty (Kolbe \& James, 2003). A sport fan's optimal internalization of a sport object is expected to manifest as loyalty to the sport object and produce strong attitudinal properties such as importance, knowledge, affect, and resistance to change (Funk \& James, 2001; Kolbe \& James, 2003). The formation of a sport identity differs for each individual based on his or her dispositional needs, individual attributes, and previous experience (Funk \& James, 2004). The fulfillment of unmet needs can lead to facilitate an internalization of a sport object, resulting in the formation of a sport identity (Funk \& James, 2004; James \& Kolbe, 2003). The catalyst to reach the higher level of the internalization continuum is one's volition (Kolbe \& James, 2003). Like fans of "real" sports, sport video gamers can internalize a sport object such as team or athlete and form a sport identity through sport video gaming. Measuring the level of internalization of a sport object among sport video gamers and examining the relationship between motives and a sport identity can advance our understanding of the sport consumption behavior of sport video gamers.

\section{Sense of Presence}

Endearing features refer to "attractive characteristics found in sport settings that highlight the significance and value of a sport object for satisfying dispositional needs” (Funk \& James, 2004, p.8). Features of sport settings highlight the psychological significance and value of a sport team as a means for satisfying dispositional needs. Similarly, attractive features of SVGs may develop and strengthen the psychological value of a sport object as well as playing a significant role in satisfying sport video gamers' dispositional needs. The desire to satisfy these needs may act as a 
catalyst in the development or maintenance of a sport identity. Some of the attractive features of SVGs are different from the attractive features of "real" sport settings. They include interactivity (Steuer, 1992; Tamborini \& Skalski, 2006), suspenseful and violent content (Raney, Smith, \& Baker, 2006), reality (Crawford, 2004), a sense of presence (Lee, 2004; Tamborini \& Skalski, 2006), and social interaction (Crawford, 2004). Those characteristics of SVGs may be influential to fulfilling psychological needs and to develop or maintain a personal connection with a sport object. The key feature of video games is a sense of presence. Many video games provide a sense of "being there" inside the game world, a feeling referred to as "presence" (Tamborini \& Skalski, 2006). Tamborini and Skalski (2006) said that "presence can be understood as a psychological state in which the person's subjective experience is created by some form of media technology with little awareness of the manner in which technology shapes this perception.” While some researchers measure a sense of presence as unidimensional (Ryan, Rigby, \& Przybylski, 2006), the concept of presence is multidimensional (Lee, 2004; Tamborini \& Skalski, 2006; Witmer, Jerome, \& Singer, 2005). Lee (2004) redefined the concept of presence as "a psychological state in which virtual objects are experienced as actual objects in either sensory or nonsensory ways” (p. 37) and identified three subtypes of presence; physical, social and self-presence. Physical presence can be understood as the sense of being physically located in a virtual environment (Biocca, 1997). Social presence refers to the experience of virtual social actors as actual social actors (Lee, 2004). In the sport video gaming context, players can experience social presence when they respond to game characters or avatars (e.g., athletes to be controlled by them or the SVG) as if they were real. Self-presence can be defined as "a psychological state in which virtual self/selves are experienced as the actual self in either sensory or non-sensory ways” (Lee, 2004, p.46). The experience of self-presence is important in video games because it indicates the self-identification of a video gamer with or empathy with the game character. Since a video gamer interacts with the game and actually plays the role of the game character, the effect of self-identification derived from the feeling of self-presence becomes more important to enjoyment.

Proposition 2: The internalization process is moderated by the interaction between motives and a sense of presence.

\section{Mental model approach}

Mental model refers to the cognitive representation of external reality, the entities found in the situation, the interrelationships between the various entities and the situation, and events that occur in that situation (Roskos-Ewoldsen, Roskos-Ewoldsen, \& Carpentier, 2002). A mental model approach can be used as a framework to understand media effects on audiences' perceptions and behavior and explain both short-team media priming and long-term media priming. Tamborini and Skalski (2006) argued that video gamers can develop mental models through virtual experiences (i.e., video gaming) in ways thought to be unique to the actual experience because video games require immersion and involvement when playing. The rehearsal of decision making is critical because active decision making makes gamers feel the sense of presence and to form mental models. From this perspective, the sense of presence is assumed to strengthen the effect of video games on actual behaviors. Since SVGs provide the entire experience of playing a sport including playing a single game, drafting, and even business decisions such as franchise relocation (Leonard, 2006), various decisions made in association with playing a sport video games can foster a mental model of a sport identity.

Proposition 3: A sense of presence directly contributes to a sport identity. 


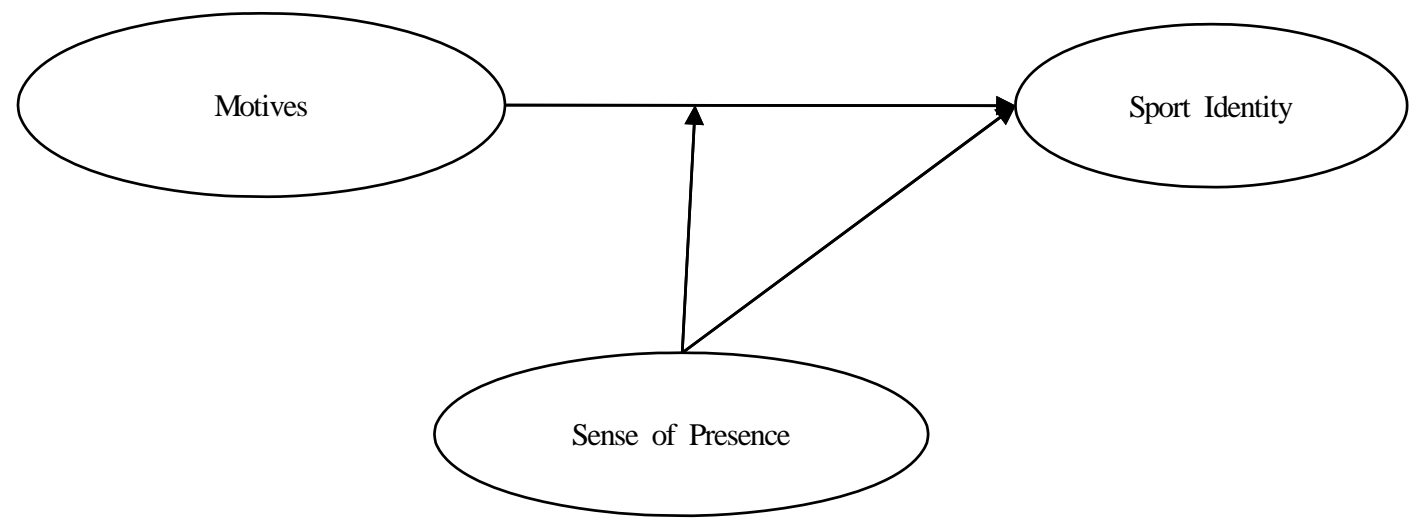

Figure 1. The proposed model of internalization of a sport object through sport video gaming.

Based on the FAN model and the mental model approach, the internalization model of a sport object through sport video gaming was proposed (see Figure 1). The model assumes the relationship between motives and a sport identity, the relationship between a sense of presence and a sport identity, and the interaction effect between motives and a sense of presence on a sport identity.

\section{Discussion and Future Research}

The proposed model is based on the premise that motives to play SVGs and a sense of presence will contribute to a sport identity. The identity in question is team identity. The focus on team identity is based in part on the expectation that sport video gamers are expected to choose their favorite teams from real life (Kim \& Ross, 2006) when playing SVGs. The current study provides a conceptual framework to better understand psychological aspects of sport consumer behavior in terms of sport video gaming. The proposed model depicts the relationships among motives, a sense of presence, and a sport identity based on the FAN model (Funk \& James, 2004). The FAN model proposed the relationship between motives to consume sports and a sport identity and an interaction effect between motives and endearing features of sport (e.g., performance outcomes, environment, and quality of service) on a sport identity. However, the current study hypothesized the direct relationship between a sense of presence as one of the attractive features of sport video games and a sport identity based on the mental model approach (Roskos-Ewoldsen, Roskos-Ewoldsen, \& Carpentier, 2002). Future research should empirically test the proposed model to understand psychological aspects of sport consumption behavior in terms of sport video gaming context.

The proposed model in the study was related with only the first part within the Fan Attitude Network (FAN) model (Funk \& James, 2004), the relationship between dispositional needs and a sport identity and the moderating effect of endearing features of sports on the relationship between dispositional needs and a sport identity. Researchers may apply the current model to the full structural model of attitude formation and change (e.g., FAN model) in terms of sport video gaming. Funk and James (2004) noted that attitude formation and change occurs: "When the psychological significance and value derived from a sport identity become salient to an individual. In other words, the extent to which attitude formation and change takes place depends upon the perception that the sport identity satisfies dispositional needs" (p.8). If an individual forms a sport identity by satisfying his or her dispositional needs through sport video gaming, his or her atttiude toward the sport object can be enhanced and attitude importance may influence four outcomes 
including persistence, resistance to change, biases in cognitive processing, and consistency with past behavior and behavioral intent. By examining the full structural model (e.g., FAN model) in terms of sport video gaming, researchers may provide practicioners with more detailed information with regard to psychological perspectives of sport video gamers.

\section{References}

Beall, G.(2016, November 5). 8 Key differences between Gen Z and millennials. HUFF Post. https://www. huffingtonpost.com/

Bennett, G., Henson, R.K., \& Zhang, J. (2003). Generation Y's perceptions of the action sports industry segment. Journal of Sport Management, 17, 95-115. https://doi.org/10.1123/jsm.17.2.95

Bennett, G., \& Lachowetz, T. (2004). Marketing to lifestyle: Action sports and Generation Y. Sport Marketing Quarterly, 13(4), 239-243.

Bennett, G., Sagas, M., \& Dees, W. (2006). Media preferences of action sports consumers: Differences between generation $\mathrm{X}$ and $\mathrm{Y}$. Sport Marketing Quarterly, 15(1), 40-49.

Biocca, F. (1997). The cyborg's dilemma: Progressive embodiment in virtual environments. Journal of Computer-Mediated Communication, 3(2), https:// doi.org/10.1111/j.1083-6101.1997.tb00070.x

Crawford, G. (2004). Consuming sport: Focus, sport and culture. New York, NY: Routledge.

Funk, D.C., \& James, J.D. (2001). The Psychological Continuum Model: A conceptual framework for understanding an individual's psychological connection to sport. Sport Management Review, 4, 119-150. https://doi.org/10.1016/S1441-3523(01) $70072-1$

Funk, D.C., \& James, J.D. (2004). The fan attitude network model: Exploring attitude formation and change among sport consumers. Sport Management Review, 7, 1-26. https://doi.org/10.1016/S1441-35 23(04)70043-1
Funk, D.C., \& James, J.D. (2006). Consumer loyalty: The meaning of attachment in the development of sport team allegiance. Journal of Sport Management, 20, 189-217.

Funk, D.C., \& Pastore, D.L. (2000). Equating attitudes to allegiance: The usefulness of selected attitudinal information in segementation loyalty to professional sports teams. Sport Marketing Quarterly, 9, 175-184.

Kim, Y., \& Ross, S.D. (2006). (2006). An exploration of motives in sport video gaming. International Journal of Sports Marketing \& Sponsorship, 34-46. https://doi.org/10.1108/IJSMS-08-01-2006-B006

Kim, M.S., \& Han, J. (2012). The effect of sport video gamers' motives on team identification: Moderating role of gender, Korean Journal of Sport Managemen, 17(1), 63-77.

Kim, M.S., \& Kwon, H.H. (2010). A development of a motivation scale for sport video Gaming (MSSVG). Journal of Sport and Leisure Studies, 39, 49-62.

Kolbe, R.H., \& James, J.D. (2003). The internalization process among team followers: Implications for team loyalty. International Journal of Sport Management, 4(1), 25-43.

Lee, K.M. (2004). Presence, explicated. Communication Theory, 14(1), 27-50. https://doi.org/10.1111/j.14682885.2004.tb00302.x

Leonard, D. (2006). An untapped field: Exploring the world of virtual sports gaming. In A.A. Raney \& J. Bryant (Eds.), Handbook of sports and media (pp. 393-408). Mahwah, NJ: Lawrence Erlbaum Associates.

Murrell, A.J., \& Dietz, B. (1992). Fan support of sport teams: The effect of a common group identity. Journal of Sport \& Exercise Psychology, 14(1), 28-39.

Raney, A.A., Smith, J.K., \& Baker, K. (2006). Adolescents and the appeal of video games. In P. Vorderer \& J. Bryant (Eds.), Playing video games: Motives, responses, and consequences (pp. 165-179). Mahwah, NJ: Lawrence Erlbaum 
Associates.

Roskos-Ewoldsen, D.R., Roskos-Ewoldsen, B., \& Carpentier. F.R. (2002). In J. Bryant \& d. Zillmann (Eds.), Media effects. Advances in theory and research (2nd ed.), (pp. 97-120). Mahwah, NJ: Lawrence Erlbaum Associates.

Ryan, R.M., Rigby, C.S., \& Przybylski, A. (2006). The motivational pull of video games: A self-determination theory approach. Motivation and Emotion, 30(4), 347-363. https://doi.org/10.1007/ s11031-006-9051-8

Spitznagel, E. (2020, January 25). Generation Z is bigger than millennials and they're out to change the world. New York Post. https://www.nypost.com/

Tamborini, R., \& Skalski, P. (2006). The role of presence in the experience of electronic games. In P. Vorderer \& J. Bryant (Eds.), Playing video games: Motives, responses, and consequences (pp. 225-240). Mahwah, NJ: Lawrence Erlbaum Associates.

Wann, D.L., \& Branscombe, N.R. (1990). Die-hard and fair-weather fans: Effects of identification on BIRGing and CORFing tendencies. Journal of Sport and Social Issues, 14(2), 103-117. https://doi. org/10.1177/019372359001400203

Wheaton, B., \& Thorpe, H. (2018). Action sport media consumption trends across generations: Exploring the Olympic audience and the impact of action sport inclusion. Communication \& Sport, 7(4), 415-445. https://doi.org/10.1177/2167479518780410

Witmer, B.G., Jerome, C.J., \& Singer, M.J. (2005). The factor structure of the presence questionnaire. Presence, 14(3), 298-312. https://doi.org/10.1162/ 105474605323384654 